\title{
Design of Generator Stator Protection 100\% Using Overvoltage and Undervoltage Schemes
}

\author{
aAli Mashar*, aMaula Zahara Firdausi, aAchmad Mudawari, aAchmad Deni Mulyadi, \\ aDjafar Sodiq
}

aDepartment of Energy Conversion Engineering, Politeknik Negeri Bandung, Bandung 40559, Indonesia

Received 12 August 2019; accepted 15 December 2019

\begin{abstract}
Nowadays, there are still many high capacity generators have not yet protected completely from their internal ground faults. They still rely on differential and over current relays. It is seen that this relay will reduce their sensitivities when applied to generators with high impedance grounding systems. To overcome such problem, a combination protection scheme of the neutral overvoltage $(59 \mathrm{~N})$ and neutral undervoltage third harmonics $(27 \mathrm{~N} 3)$ is developed. This paper aims to design the protection scheme for high capacity generators. This paper demonstrates the designing of neutral grounding transformer (NGT) system, the relay settings and reviewing of their sensitivities. To clarify the concepts this study uses a generator 802 MVA, $22.8 \mathrm{kV}$ as object. The results show that the protection scheme is very effective to protect $100 \%$ of generator stator with relays overlapping of $31.5 \%$. It needs NGT transformer with capacity of only $28.33 \mathrm{kVA}, 15000 / 240$ $\mathrm{V}$, and the secondary resistor of $0.38,117 \mathrm{~kW}$. This paper can hopefully be used as one reference for protection system engineers to design or develop protection schemes in their fields especially whose generator has not equipped yet with such protection scheme.
\end{abstract}

\section{KEYWORDS}

Neutral grounding transformer (NGT) Secondary resistor Relay settings Relay sensitivity Relay overlapping

\section{INTRODUCTION}

Synchronous generator is a very expensive equipment and has so vital roles in power plant systems. The machine must be protected as perfect as possible in order not to suffer damage in case of all sorts of faults, one of which is a ground fault at internal parts of generator. The ground fault protection schemes and neutral grounding methods have been well explained in (IEEE, 1993). In general, to overcome generator internal fault still rely on differential and over current ground fault relays. The fact shows that these relays are reducing their sensitivity when applied to generator using high impedance grounding systems in particular for ground faults that occur in areas near neutral points. To solve the problem, a new study of the neutral Overvoltage relay protection and third harmonic relay schemes emerged. With the combination of these two relays expected to be able to protect the overall stator generator (100\%). 
In Indonesia, the authors have found many generators in relatively new power plants with very high capacities do not equipped with such protection. Based on this, the authors are interested in how to modify the existing protection with a new protection mentioned above.

The purpose of this paper is to demonstrate how this generator stator $100 \%$ protection scheme is designed and applied to protect a relatively high capacity generator used in a power plant in Indonesia. For this purpose, the study uses a generator, $802 \mathrm{MVA}, 22.8 \mathrm{kV}$ which did not use this protection scheme. The paper will demonstrate how to design the protection scheme induding the setting and evaluating its sensitivity.

\section{THE CONCEPT OF GENERATOR STATOR 100\% PROTECTION SCHEME}

There are many schemes of protection 100\% stator winding and (Pope, 1984) has made comparison of them. Then (Marttila, 1986) introduce new protection schemes of such protection. (Klingerman, 2016) introduces the principles of generator stator protection can be fulfilled by combining neutral overvoltage fundamental and third harmonic relays or subharmonics injection relay. This paper will introduce one of such methods, namely: the combination of neutral overvoltage and under voltage third harmonics relays protection system as shown Fig. 1.

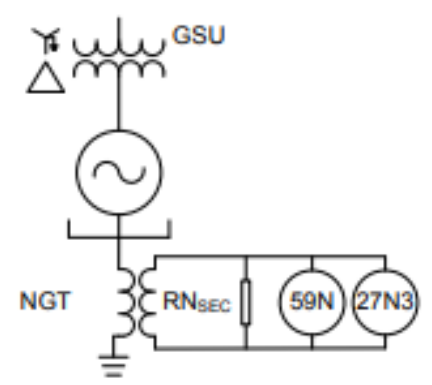

Figure 1. Schematic diagram of generator stator protection $100 \%$

Here, the generator is connected to a grid system by a generator transformer unit in delta. Generator uses a neutral grounding transformer (NGT) with generator neutral connected to the ground through the primary transformer and the two relays are installed at the secondary parallel to secondary resistance $\mathrm{R}_{\mathrm{Nsec}}$. The need of NGT is for reducing fault current to protect the stator generator. For generator with voltage $18 \mathrm{kV}$ and higher the fault current should be limited to $1 \mathrm{~A}$ (Xiaobo L., 2010).

\section{Neutral overvoltage protection scheme}

Figure 2 shows a generator connected to an electrical grid system through the generator transformer (GT) connected in delta-star. When there is a transformer for self-use (UAT), it is also in delta-star connection. The generator uses a high impedance grounding system NGT with a resistor and a relay overvoltage $(59 \mathrm{~N})$ mounted on the secondary transformer. The Relay is installed only to measure the fundamental voltage $(50 \mathrm{~Hz})$ at the secondary transformer. 
Under normal operation, no current flows through the NGT, so the voltage on the resistor grounding and the $59 \mathrm{~N}$ relay is zero. Conversely, when a ground fault occurs on the stator, there will be a fault current flowing through the NGT and causing voltage across resistor on the secondary transformer. The overvoltage relay measures the magnitude of voltage and thereby detects the ground fault on the stator winding.

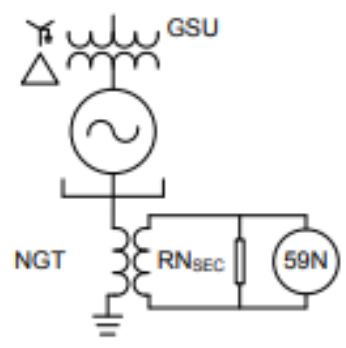

Figure 2. Generator with neutral overvoltage protection (59N)

This is a protection scheme which capable of detecting ground fault in most of the stator winding. How this protection scheme is able to detect ground faults that are likely to occur in most of the stator, illustrated in Figure 3.

This figure illustrates the relationship between the location (point) of ground faults at the stator winding and the voltage across the grounding resistor, with the ground fault occurring at the A-phase stator terminal. Based on the analysis it was found that large neutral resistance of primary in $k \Omega$ range. Therefore, the series impedance of the stator and line-to neutral generator capacitance can be ignored (since it is much smaller compared to the grounding impedance).

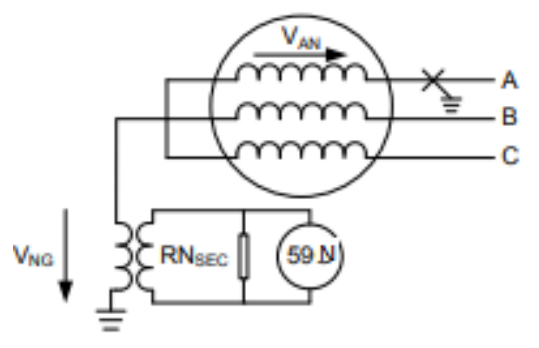

Figure 3. Wiring diagram with fault in terminal stator of phase-A

When ground fault occurs at phase $\mathrm{A}$, the voltage in the NGT $\left(\mathrm{V}_{\mathrm{NG}}\right)$ is equal to the phaseneutral voltage generated by the generator $\left(\mathrm{V}_{\mathrm{AN}}\right)$. In other words, phase-to-ground shortcircuited fault on the terminal stator generator generates a nominal phase-neutral voltage generator on the primary side of NGT. Thus, in principle every fault at any position the stator can be calculated.

Note Figure 4 assuming the fault occur at $\mathrm{x}$, where $\mathrm{x}$ is the fault location measured from the neutral point $(\mathrm{N})$ in per unit $(\mathrm{pu})$. The voltage from the neutral point of the generator $(\mathrm{N})$ to the fault point ( $\mathrm{x}$ ) is equal to $\mathrm{x}^{\bullet} \mathrm{V}_{\mathrm{PN}}$, and this voltage is equal to the voltage in the NGT. When the location of fault changes, the NGT voltage will also change according to the location/position of 
the fault point of the stator. Thus, it can be said that the NGT voltage is directly proportional to the fault distance from the neutral point.

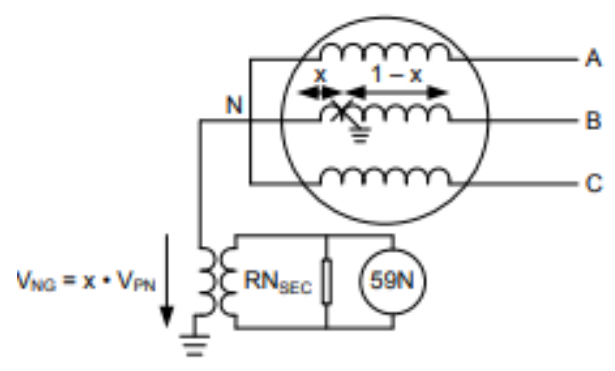

The percentage of protection coverage by the $59 \mathrm{~N}$ element can be calculated as:

$$
59 N \text { coverage }(\%)=\frac{V G_{R A T E D}-\text { Pickup }_{59 G N} \cdot N_{N G T}}{V G_{R A T E D}}
$$

The problem with overvoltage relay, as stated in (Klingerman, 2016), there are about 5-10\% area near the neutral point of the generator that is not covered by this relay. On this basis, another scheme was developed to gain $100 \%$ coverage, by combining this protection with neutral undervoltage third harmonics.

\section{Neutral undervoltage third harmonics protection scheme (27N3)}

In fact, harmonic voltage is always produced when generator operating in normal condition (unfaulty). The occurrence of the voltage resulted from the limitation in the design of the machine physically. The most dominant harmonic voltage is the third-harmonic voltage and this voltage is a zero-sequence voltage. The stator capacitances, system capacitances, and ground resistance will act as a series of voltage divider zero sequence networks. This causes the third-harmonics voltage to divide the entire stator winding and produce voltages with characteristic as shown in Figure 5 .

By selecting of NGR (neutral grounded resistor), the generated third harmonic voltage will be distributed evenly across the stator winding, and this voltage becomes zero at certain points in the stator (X1 or X2 in Figure. 6). The Y-axis on the left side indicates the third harmonic voltage at the neutral and the right axis indicates the third harmonic voltage at the terminal. X-axis indicates position (\%) measured from neutral stator. Dashed lines show a third-harmonized voltage distribution on a healthy generator at various load conditions and these voltages are considered linear. 


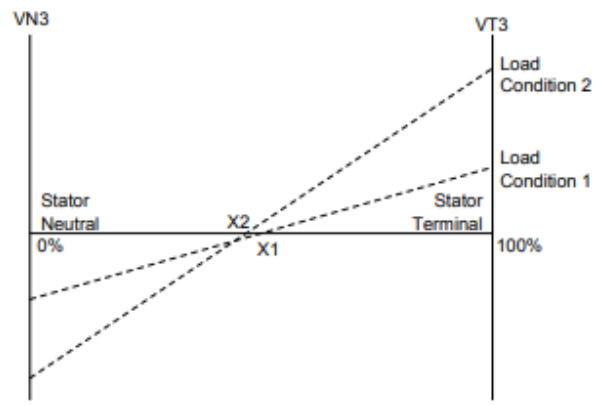

Figure 5. Third-harmonics voltage distribution at various load conditions

Figure 6 shows a third-harmonic voltage distribution in the case of fault and generator on load condition. Ground fault at the neutral makes the curve shift upwards (top row). Similarly, the ground fault at the terminal makes the shifting aurve down (bottom line).

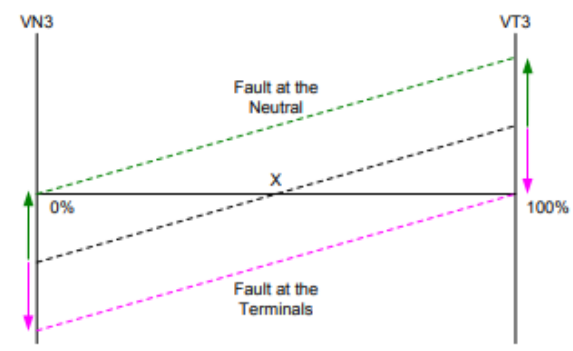

Figure 6. Third harmonic-voltage curve shift due to faults at the neutral and terminal

The third harmonic-voltage on the resistor grounding $\left(\mathrm{V}_{\mathrm{N}_{3}}\right)$ can be detected and used to detect fault-ground near neutral generators, as shown in Figure 7.

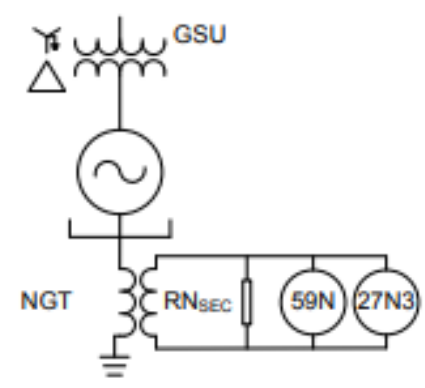

Figure 7. Generator with overvoltage $(59 \mathrm{~N})$ and undervoltage harmonic-third $(27 \mathrm{~N} 3)$ protections

\section{The undervoltage relay setting (27N3)}

Suppose that at under certain load conditions, the distribution of un-faulted third harmonic voltage as shown in Figure 8. 


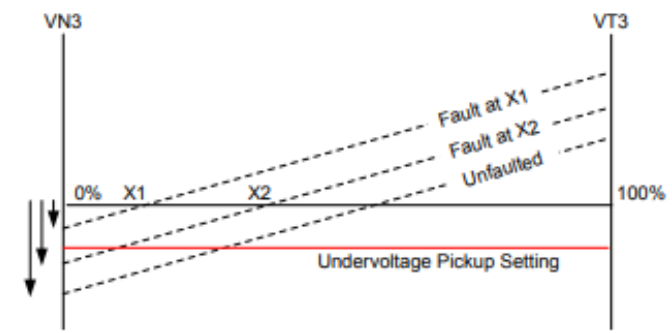

Figure 8. Shifting of third harmonic voltages at two faults close to neutral

The pickup setting should be at a safe margin, i.e. under VN3 at no fault condition. Now assume that the fault occurs at X1. The VN3 will drop below the pickup setup and the protection will operate. Then, assume that the fault is moved to $\mathrm{X}_{2}$. VN3 is still larger than pickup and protection is not operating. In other words, the protection scheme does not reach this fault. Keep in mind that portrayal of harmonic voltage distribution requires knowledge of VT3 as well.

Prior to the $27 \mathrm{~N} 3$ setting up element, it was very important to measure the third-harmonic voltage in many different operating conditions to confirm that the setting of the element is done appropriately. Concerning with this [R.L. Schalke, 1981] states that the third-harmonic voltage generated by generator is affected by the condition of the loads. At a light load the third-harmonic voltage is lower than the third-harmonic voltage at no-load condition, while at full load is the highest written as follow:

- The third-harmonic voltage at no load condition is:

$$
V_{3 \text { no load }}=1,3 \% \times V_{L-L}
$$

- The third-harmonic voltage at light load condition is:

$$
V_{3 \text { light load }}=57 \% \times V_{3 \text { no load }}
$$

- The third-harmonic voltage at full load condition is:

$$
V_{3 \text { full load }}=200 \% \times V_{3 \text { no load }}
$$

\section{Sensitivity and coverage of $27 \mathrm{~N} 3$ element}

The sensitivity of the third-harmonic undervoltage relay $\left(27 \mathrm{~N}_{3}\right)$ depends on the generator's voltage characteristic. The general guideline for this pickup element is (IEEE, 2000, Std C62.92.1): 


$$
\text { Pickup }_{27 N 3}=\frac{V N 3_{M I N}}{2}
$$

where:

VN3MIN: minimum third-harmonic voltage at neutral

Pickup $_{27 \mathrm{~N}_{3}}$ : undervoltage relay pickup

To set $27 \mathrm{~N} 3$ relay, it needs to know the third-harmonic voltage at both the neutral and the terminal stator. The equivalent circuit is shown in Figure 9. From this figure the third-harmonic voltage at both neutral and terminal can be calculated.

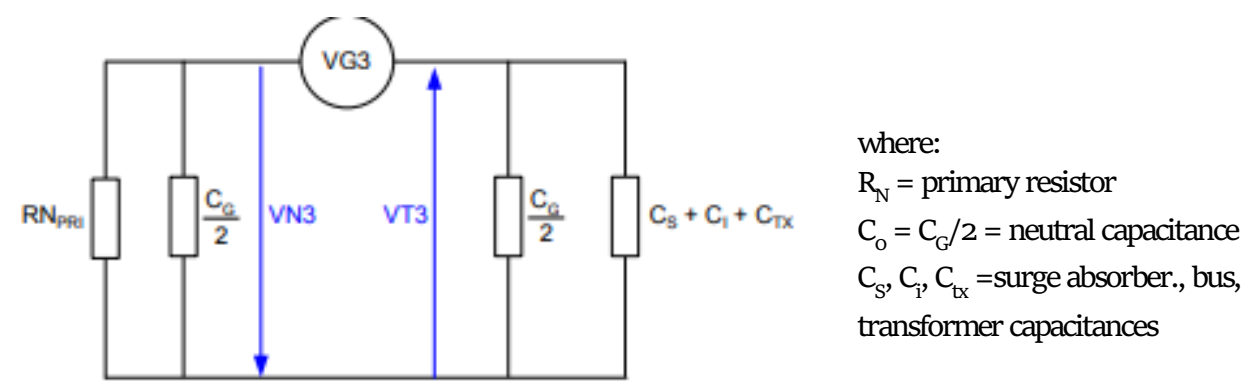

Figure 9. Third harmonics equivalent circuit

Based on the equivalent circuit (Figure. 9), the third-harmonic voltages are shown in Figure 10. With the setting of $0.5 \times \mathrm{V}_{\mathrm{N} 3 \mathrm{MIN}}$, it can be estimated that element coverage is $25 \%$ measured from the neutral as shown in the figure. As $59 \mathrm{~N}$ reaches $90-95 \%$ of stator (measured from terminal), these two elements will provide overlap.

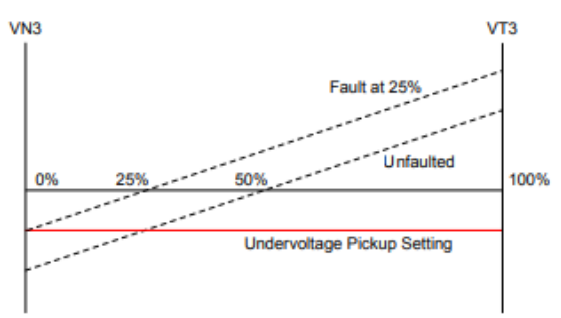

Figure 10. The $27 \mathrm{~N} 3$ range for pickup setting at $50 \% \mathrm{~V}_{\mathrm{N} 3 \mathrm{MIN}}$

\section{Stator Protection Scheme 100\%}

To get the coverage of $100 \%$ stator generator protection using fundamental overvoltage protection $(59 \mathrm{~N})$ and third-harmonic undervoltage is shown in Figure 7, the Overvoltage 59GN relay detects faults in 90-95\% stator, while the remaining $5-10 \%$ is covered by undervoltage distortion relay (27N3). The $59 \mathrm{~N}$ relay measures the voltage fundamental frequency of $5 \mathrm{OHz}$, and a $27 \mathrm{~N} 3$ relay as an undervoltage relay with frequency $150 \mathrm{~Hz}$ (Klingerman, 2016]. By combining $59 \mathrm{~N}$ relay and the $27 \mathrm{~N} 3$ relay this system will protect the entire of stator generator. 


\section{RESULTS AND CONCLUSION}

\section{Generator and main transformer specification}

Table 1 presents the specification data of the equipment system capacitances required for this study. The generator is connected with Generator Transformer (NGT) and Auxiliary Transformer units (UAT) complete with surge absorber etc. This capacitance data is necessary to determine the NGT transformer impedance.

Table 1. Equipment capacitances

\begin{tabular}{lcc}
\hline \multicolumn{2}{c}{ Equipment } & capasitance line to ground, $\mathrm{C}_{\mathrm{o}}(\mu \mathrm{F})$ \\
\hline $\begin{array}{l}\text { Generator 802 MVA, 22.8 kV } \\
\text { (C Cen) }\end{array}$ & $0.33 \mu \mathrm{F}$ \\
Surge & $\mathrm{CS}_{\mathrm{a} 1}$ & $0.13 \mu \mathrm{F}$ \\
absorber & $\mathrm{CS}_{\mathrm{a} 2}$ & $0.13 \mu \mathrm{F}$ \\
& $\mathrm{C}_{\mathrm{VT}}$ & $0.10 \mu \mathrm{F}$ \\
& $\mathrm{C}_{\mathrm{GT}}$ & $0.43 \times 10^{-2} \mu \mathrm{F}$ \\
Transformer & $\mathrm{C}_{\mathrm{UT} 1}$ & $0.11 \times 10^{-1} \mu \mathrm{F}$ \\
& $\mathrm{C}_{\mathrm{UT} 2}$ & $0.11 \times 10^{-1} \mu \mathrm{F}$ \\
IPB (Isolated & $\mathrm{C}_{\mathrm{Ext}}$ & $0.02 \times 10^{-2} \mu \mathrm{F}$ \\
Phase Bus) & $\mathrm{C}_{\mathrm{IPB}}$ & $0.925 \times 10^{-3} \mu \mathrm{F}$ \\
\hline
\end{tabular}

\section{Determination of NGT System}

Author has described in (Mashar et. al, 2019) the detail of how the NGT system is designed for this protection scheme. Even so to keep its integrity, it will be reviewed again here.

- Determination of the primary resistance of transformer (Rn)

The capacitance to the neutral is the value of all the capacitance connected in parallel, so the total capacitance of the system to neutral $\left(\mathrm{C}_{0}\right)$ is:

$$
\mathrm{C}_{\mathrm{O}}=\mathrm{C}_{\mathrm{Gen}}+\mathrm{Cs}_{\mathrm{a} 1}+\mathrm{Cs}_{\mathrm{a} 2}+\mathrm{C}_{\mathrm{VT}}+\mathrm{C}_{\mathrm{GT}}+\mathrm{C}_{\mathrm{UT} 1}+\mathrm{C}_{\mathrm{UT} 2}+\mathrm{C}_{\mathrm{Ext}}+\mathrm{C}_{\mathrm{IPB}}=0.717425 \mu \mathrm{F}
$$

Thereby, the reactance can be calculated as:

$$
\begin{aligned}
& X_{c o}=\frac{1}{\omega C o} \\
& X_{c o}=\frac{1}{2 \pi f C o}=4436.84 \Omega
\end{aligned}
$$


Then capacitive reactance to the ground $(\mathrm{Xcg})$ is:

$$
\begin{aligned}
& X_{c g}=\frac{X c o}{3 \phi} \\
& X_{c g}=\frac{4436.84 \Omega}{3}=1478.94 \Omega
\end{aligned}
$$

In standard the primary neutral resistor value $(\mathrm{Rn})$ is selected equal to $\mathrm{Xcg}$, or:

$$
\begin{aligned}
R_{n} & =X_{c g} \\
& =1478.94 \Omega
\end{aligned}
$$

\section{- Secondary resistance}

The secondary resistance Rsec can be determined after having the transformer ratio. The minimal NGT primary voltage should be the same as one-phase generating voltage plus the anticipation voltage fluctuation in the network system (5-10\%). Therefore, the primary voltage is selected slightly higher.

If the nominal voltage of the generator is $22800 \mathrm{~V}$, then the phase voltage is $22800 / \mathrm{V} 3$ $=13164 \mathrm{~V}$. From this, the selected transformer is a transformer with primary voltage 15000 V. About the secondary voltage, there are two options, namely: $110 \mathrm{~V}$ or $240 \mathrm{~V}$. In this case the selected secondary voltage is $240 \mathrm{~V}$, the NGT transformer ratio is:

$$
N=\frac{15000}{240}=62.5
$$

Thus the secondary resistor (Rsec):

$$
\begin{aligned}
R_{\text {sec }} & =\frac{R_{n}}{N^{2}} \\
& =\frac{1478.94}{62.5^{2}}=0.38 \Omega
\end{aligned}
$$

In addition to its resistance, another important aspect of the resistor is its power capacity. A secondary resistor power capacity can be determined based on the power dissipation in the resistor and the secondary current is:

$$
\begin{aligned}
I_{\text {sec } \max } & =\frac{V_{\text {gen }}(L-L)}{\sqrt{3}} \times \frac{1}{N} \times \frac{1}{R_{\text {sec }}} \\
& =\frac{22800}{\sqrt{3}} \times \frac{1}{62,5} \times \frac{1}{0,38} \\
& =554.25 \mathrm{~A}
\end{aligned}
$$


MASHAR ET.AL

The power capacity of secondary resistor ( $\mathrm{Pr}$ ) when a fault occurs is

$$
\begin{aligned}
P r & =I_{\text {sec } \max }{ }^{2} \times R_{\text {Sec }} \\
& =554.25^{2} \times 0.38 \\
& =116733.36 \mathrm{~W} \approx 117 \mathrm{~kW}
\end{aligned}
$$

Thus, the secondary resistor $R_{\text {sec }}$ has a specification of: $0.38 \Omega, 117 \mathrm{~kW}$

\section{- NGT Capacity}

The transformer capacity can be determined as follows:

$$
\begin{aligned}
S & =I s e c \cdot V s e c \\
& =133 \mathrm{kVA}
\end{aligned}
$$

The calculation shows that NGT capacity is $133 \mathrm{kVA}$. Since it works only in the event of fault which is in a very short time, the transformer capacity can be lowered by considering the duration of the fault. Dann and Montsinger provide assistance as stated in (IEEE, 2017) and (IEEE, 2006) as shown in Table 2.

Table 2. Equipment capacitances

\begin{tabular}{cc}
\hline Duration of Overload & Multiple of rated kVA \\
\hline $10 \mathrm{~s}$ & 10.5 \\
$60 \mathrm{~s}$ & 4.7 \\
$10 \mathrm{~min}$ & 2.6 \\
$30 \mathrm{~min}$ & 1.9 \\
$2 \mathrm{~h}$ & 1.4 \\
\hline
\end{tabular}

This table provides hints of down-rating multiplier factors kVA of distribution transformers for NGT. The transformer capacity can be lowered according to the fault duration chosen and the transformer kept safely. In this case, it takes fault duration of 60 second (overload duration), Then, the transformer capacity can be reduced to:

$$
\begin{aligned}
S_{T R} & =\frac{133}{4.7} \\
& =28.30 \mathrm{kVA}
\end{aligned}
$$

Thus, NGT specification for this protection requirement is $15000 / 240 \mathrm{~V}, 28.30 \mathrm{kVA}$.

\section{Third-harmonic voltage calculations}

To ensure that the setting of relay $27 \mathrm{~N} 3$ is done accurately, it needs to know the third harmonic voltages in both normal and abnormal conditions as function of distance from neutral point with $\mathrm{R}_{\mathrm{sec}}: 0.38 \Omega$. 
1. Third-harmonic voltage at normal conditions

In normal condition, generator will produce third-harmonic voltages by variation of load conditions. The result is shown in Table 3 (by Matlab \& Simulink). There are third-harmonic voltages here: generated by generator (V3), at the neutral (VN3) and at the terminal (VT3).

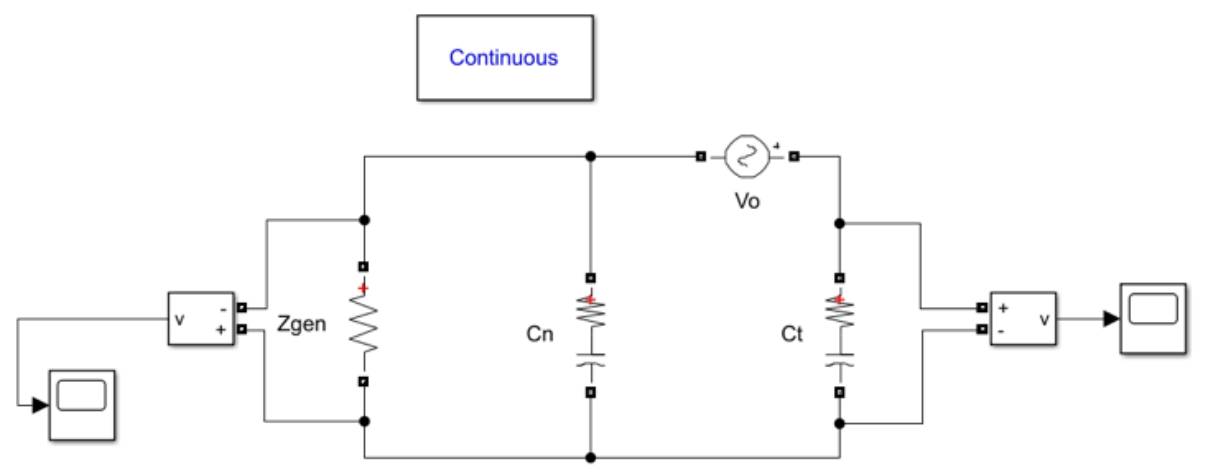

Figure 11. Simulation equivalent circuit for normal condition

Table 3. The calculation results

\begin{tabular}{cccc}
\hline Load conditions & $\boldsymbol{V}_{\mathbf{3}}(\mathrm{V})$ & $\boldsymbol{V}_{\mathbf{3 n}}(\mathrm{V})$ & $\boldsymbol{V}_{3 \boldsymbol{t}}(\mathrm{V})$ \\
\hline No load & 296,40 & $214,70<18,71^{\circ}$ & $114,91<-36,69^{\circ}$ \\
Light load & 168,95 & $122,50<18,71^{\circ}$ & $65,80<-36,69^{\circ}$ \\
Full load & 592,80 & $429,30<18,71^{\circ}$ & $231,10<-36,69^{\circ}$ \\
\hline
\end{tabular}

2. Third-harmonic voltage at abnormal conditions

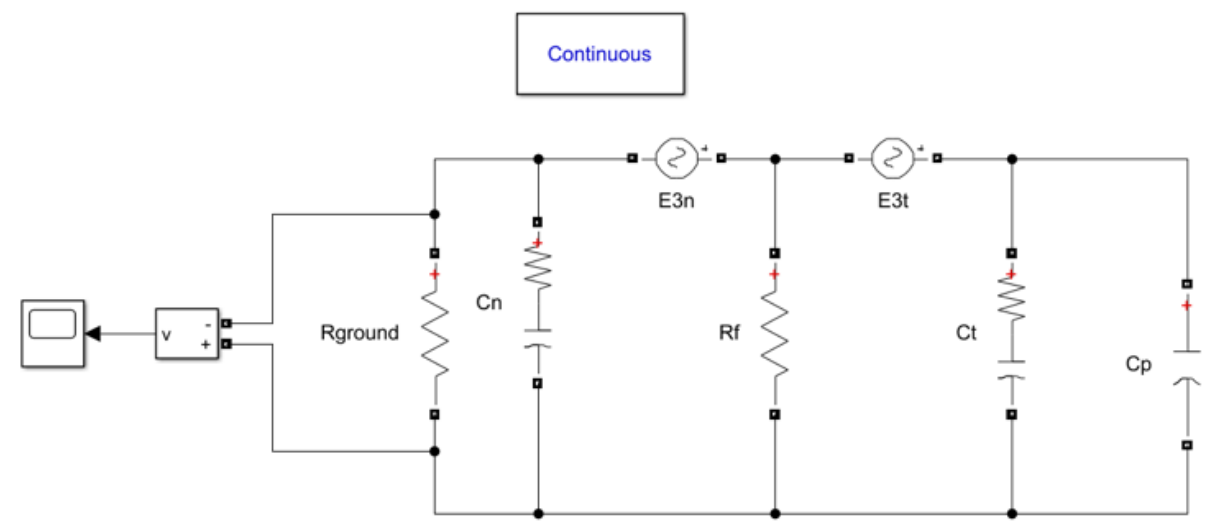

Figure 12. Simulation equivalent circuit for abnormal condition

The simulation has been done by varying the value of Rf to know the 3rd harmonic voltage distribution arises along the stator (the voltage in the primary NGT). Figure 13 shows the thirdharmonic voltages distribution as function of the distance from neutral point for variable 
MASHAR ET.AL

resistances $(0.38 \mathrm{1M})$. It shows that with higher resistance the third-harmonic voltages flatter (relatively constant). Therefore, to detect VN3 will be useful with relatively small resistance).

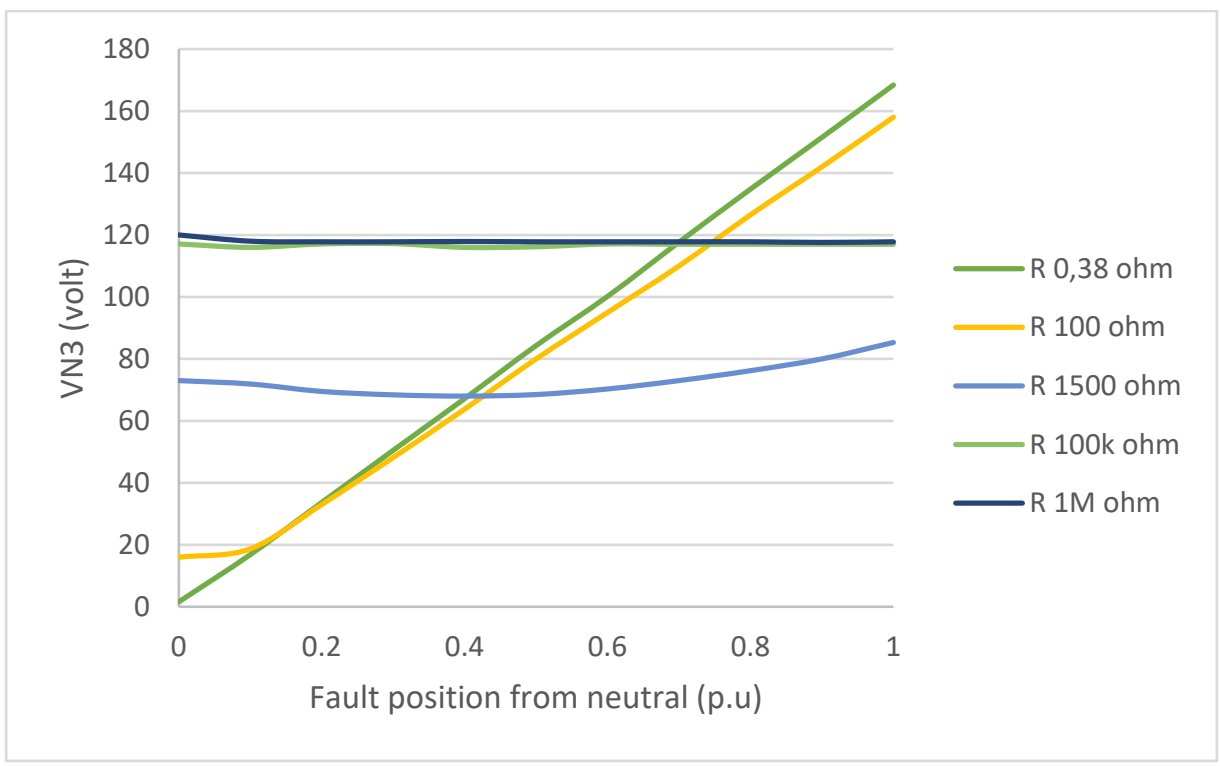

Figure 13. Third harmonic voltage distribution with Rsec variations $=0.38 \Omega-1 \mathrm{M} \Omega$

By extracting the data only with resistance of 0.38 as designed with three kinds of loading conditions: no load, light load, and full load, it will provide condition as shown in Figure 14.

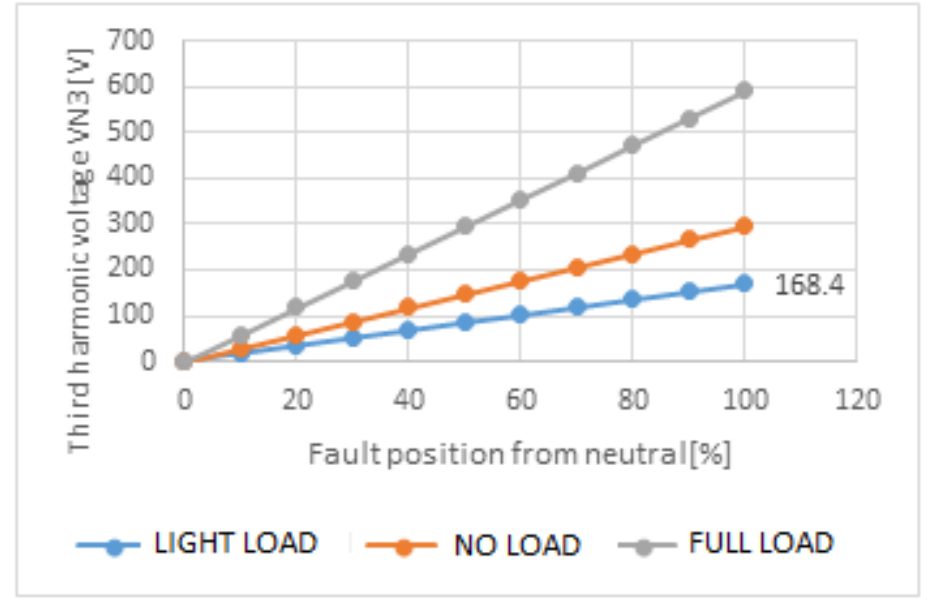

Figure 14. Third harmonic voltage distribution with $\mathrm{Rsec}=0.38 \Omega$

This indicates that the third-harmonic voltage distribution at neutral (VN3) is linear against the fault position from neutral. It is clear that the light load has the lowest harmonic voltage. If fault at the neutral VN3 is zero and if the fault at terminal (100\%), VN3 is $168.4 \mathrm{~V}$. This voltage will be used in the relay settings and overall protection performance analysis. 


\section{Relay Protection Settings}

1. Overvoltage relay $(59 \mathrm{~N})$ setting

Based on (Reimert, D, 2006,), the setting of the neutral overvoltage relay is based on the NGT secondary nominal voltage. For nominal voltage secondary $120 \mathrm{~V}$ and $240 \mathrm{~V}$, the pick up voltages in general are $6 \mathrm{~V}, 12 \mathrm{~V}$ respectively or $5 \%$ of the secondary nominal voltage. In this case with the selected secondary nominal voltage is $240 \mathrm{~V}$, then the pick up voltage for the $59 \mathrm{~N}$ relay is $12 \mathrm{~V}$. For the pick-up voltage the $59 \mathrm{Nrelay}$ has a protection coverage:

$$
\begin{aligned}
\text { Coverage 59N (\%) } & =\frac{\mathrm{VG}_{\mathrm{RATED}}-\text { Pickup }_{59 G N} \cdot \mathrm{N}_{\mathrm{NGT}}}{\mathrm{VG}_{\mathrm{RATED}}} \\
& =(22800 / \sqrt{3}-12 * 62,5) / 22800 / \sqrt{3} * 100 \% \\
& =94,33 \% .
\end{aligned}
$$

This indicates that the stator is protected for $94 \%$ from the terminal, so there are areas that are not protected of $6 \%$ from neutral generators. If the generator's nominal voltage decreases, its protective coverage will also decrease and vice versa.

\section{The Setting of undervoltage relay $(27 \mathrm{~N} 3)$}

Unlike $59 \mathrm{~N}$, the $27 \mathrm{~N} 3$ relay requires factual data about the third-harmonic voltage generated in the generator. Since it is not possible to measure directly, the study uses the data provided by R.L. Schalke, 1981 stated above.

Based on the data from Table 3, the third harmonic voltage at the neutral with variation of load conditions is plotted as shown in Figure. 15.

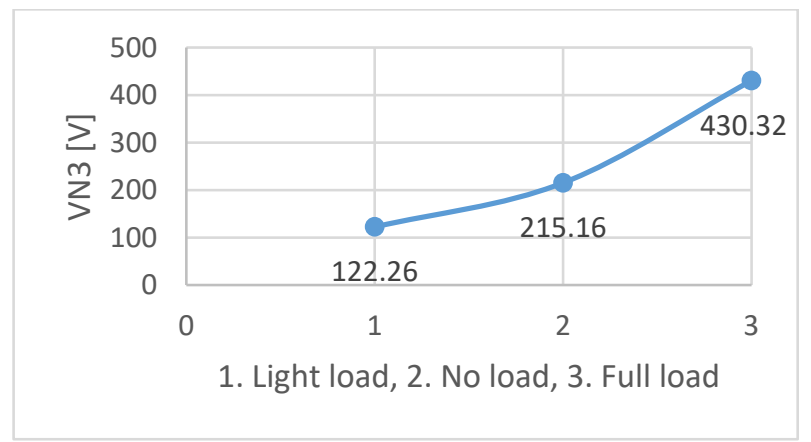

Figure 15. Third-harmonic voltage as function of loads

In the protection relay setting, it is certainly work of relay must not interfere the operation of the machine in its normal operating conditions, starting from no load, load or other conditions that do not include the category of faults or errors. Similarly, the setting of $27 \mathrm{~N} 3$ relay, it must not pick up or trip on such conditions. The setup of this undervoltage relay must be below the lowest third harmonics voltage of the normal operating conditions. 
MASHAR ET.AL

Figure 15 shows that the lowest third-harmonic voltage is at when generator on light load (VN3min), 122.65 V therefore the relay pick up must be lower than that. The secondary voltage at this condition is:

$$
\begin{aligned}
V N 3 \min _{\text {sec }} & =\frac{V N 3_{\text {min }}}{N} \\
& =\frac{122,65}{62,5} \approx 2 \mathrm{~V}
\end{aligned}
$$

It means that when the third-harmonic voltage on primary is $122,65 \mathrm{~V}$, then $\mathrm{VN} 3 \mathrm{minsec}=2 \mathrm{~V}$.

To ensure the work of the relay does not interfere with the generator operation, the pickup voltage is set lower than VN3minsec. Based on the rule of thumb the safety margin can be $50 \%$ or $75 \%$. In this study the safety margin of $50 \%$ was chosen. Therefore, the pick up voltage of the relay becomes:

$$
\begin{aligned}
V_{\text {pickup } 27 N 3} & =V N 3 \min _{\text {sec }} \times \text { safety margin } \\
& =2 \times 0,5=1,0 \mathrm{~V}
\end{aligned}
$$

Or $62,5 \mathrm{~V}$ at the primary NGT

\section{Coverage of $100 \%$ stator protection scheme}

In the analysis of protection system performance, it will review the coverage of protection relays used. The $59 \mathrm{~N}$ relay protects $94 \%$ of stator winding from the terminal part to the neutral. For the $27 \mathrm{~N} 3$ relay if it is set to $1.0 \mathrm{~V}$ on secondary or $62.5 \mathrm{~V}$ on the primary transformer.

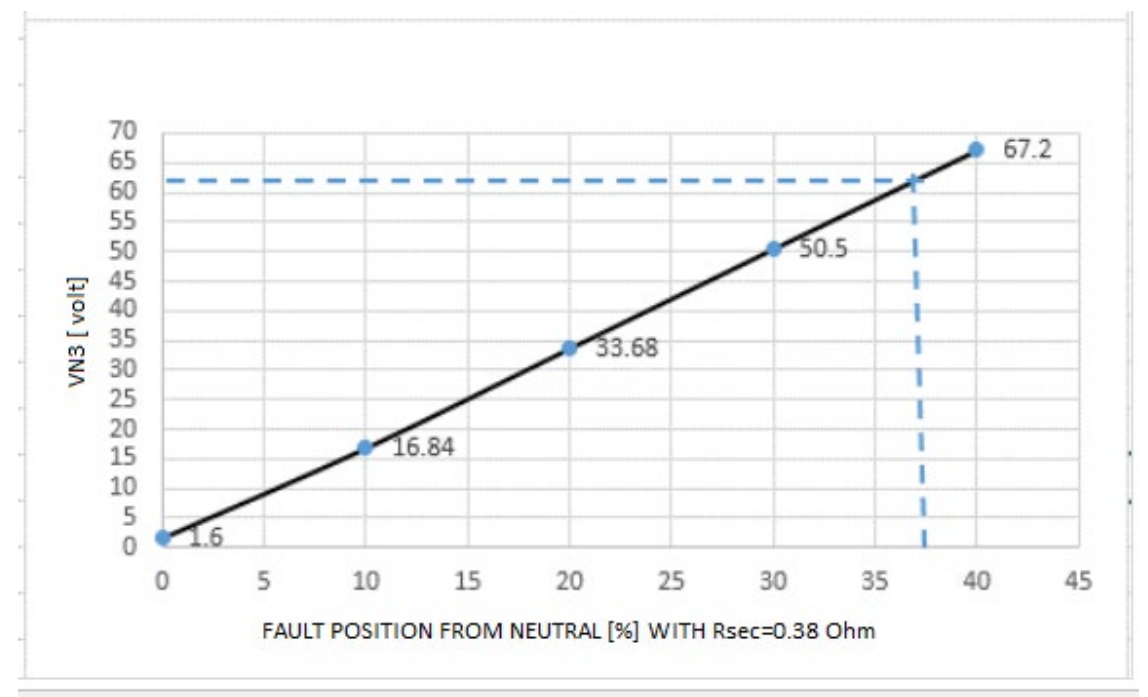

Figure 16. The $27 \mathrm{~N} 3$ relay coverage with $\mathrm{Rsec}=0.38 \Omega$ 
From Figure. 16, it is seen that if the setting at $62.5 \mathrm{~V}$ the protection has a coverage of $37.5 \%$ from the neutral point. With $59 \mathrm{~N}$ having coverage of $94 \%$ from terminal to neutral, it means both relays have overlapping of $37.5 \%-6 \%=31.5 \%$. Thus, the two relays are able to effectively protect the $100 \%$ of stator generators.

\section{CONCLUSION}

According to the results of the discussion, it can be concluded as follows:

- The combination of third-harmonic neutral undervoltage protection scheme (27N3) and neutral-overvoltage $(59 \mathrm{~N})$ works effectively on $100 \%$ stator generator protection with overlapping of 31.5\%.

- This protection scheme design requires capacitances of generator, transformer, and the network components.

- For 802 MVA generator protection, it needs an NGT transformer 28.30 kVA, 15000/240 V and a secondary resistor $\mathrm{Rsec}=0.38,117 \mathrm{~kW}$.

\section{REFERENCES}

IEEE, 1993.Std C37.101, Guide for Generator Ground Protection. USA: IEEE, Inc.

IEEE, 2017. Std C62.92.2 - 2017 Guide for The Application of Neutral Groundingin Electrical Utility Systems, Part II - Synchronous Generator Systems. New York, USA: IEEE, Inc

Marttila, R.J. 1986. Design Principles of A New Generator Stator Ground Relay for 100\% Coverage of The Stator Winding. Toronto, Canada: IEEE, Inc

Klingerman, N., 2016. Understanding Generator Stator Ground Faults and Their Protection Schemes. Atlanta, Georgia: Duke Energy \& Schweitzer Engineering Laboratories, Inc.

Pope, J.W., 1984. A Comparison of 100\% Stator Ground Fault Protection Schemes for Generator Stator Windings. USA: IEEE, Inc.

Xiaobo L., 2010, The Research and Exploiture of Subharmonic Injection Scheme for Generator Stator Ground Protection, China International Conference on Electricity Distribution

Reimert D., 2006, Protective Relaying for Power Generation Systems, Taylor \& Francis Group, London, New York

IEEE, 2000, Std C62.92.1, Guide for the Aplication of Neutral Grounding in Electrical Utility SystemsPart 1: Introduction, New York, USA: IEEE, Inc

IEEE, 2006, Std C37.102 ${ }^{\text {TM }}$-, Guide forAC Generator Protection, NewYork, USA: IEEE, Inc

Mashar, A, Hernawan, K, Firdausi, M.Z., 2019, Design of generator grounding systems for $100 \%$ generator stator protection schemes using NGT (in Indonesian), Jurnal Energi, Vol. 9, No. 1, 2019, ISSN 2089-2527. 